\title{
Flow reversal in coronary collaterals
}

\author{
P. Urban, B. Meier and L. FinCI \\ Cardiology Centre, University Hospital, 1211 Geneva 4, Switzerland
}

\begin{abstract}
KEY WORDS: Collaterals, coronary wedge pressure, angioplasty.
We report a case of collateral flow reversal observed seven months after angioplasty and due to the progression of a second lesion in another vessel. Such an occurrence has not been reported previously in association with angioplasty. Its clinical implications are discussed.
\end{abstract}

\section{Introduction}

We report a case of a patient in whom collateral flow originating from the left anterior descending coronary artery was initially associated with a right coronary artery stenosis; seven months after successful angioplasty of the right coronary artery lesion, a severe left anterior descending stenosis developed and induced reversed collateral flow from the right coronary artery through the same collateral channel. Flow reversal in collaterals has been shown to occur in an animal model ${ }^{[1]}$, following surgical bypass grafting ${ }^{[2]}$ and spontaneously in man ${ }^{[3]}$. The present report documents flow reversal in pre-existing collaterals after angioplasty. It may be a rare occurrence, but its clinical implications are significant.

\section{Case report}

A 40-year-old manual worker suffered an inferior myocardial infarction in July 1985 . Two months later, he underwent coronary angiography because of exertional angina with a positive stress test: there was inferior hypokinesia of the left ventricle with an ejection fraction of $62 \%$ and an enddiastolic pressure of $11 \mathrm{mmHg}$. There was a high grade tandem stenosis in the vertical portion of the right coronary artery [Fig. 1(a)] with collateral flow from the left anterior descending artery via a right ventricular marginal branch [Fig. 2(a)], and a proximal non significant $(30 \%)$ lesion on the left anterior descending coronary artery. Two days after successful angioplasty of the right coronary artery

Submitted for publication on 8 January 1987 and in revised form 18 May 1987.

Address for correspondence. P. Urban M.D., National Heart Hospital, Westmoreland Street, London W'IM 8BA. Telephone: (01) 4864433. lesion, a repeat stress test was negative and the patient was discharged symptom-free.

Seven months later, exertional angina recurred and a stress test was again positive. A repeat angiogram showed a moderate $(60 \%)$ restenosis of the right coronary lesion as well as a severe $(90 \%)$ stenosis at the site of the previously non-significant lesion of the left anterior descending coronary artery [Fig. 1(b)]. Right to left collateral flow was visible through the same right ventricular marginal branch that had previously served as a left to right collateral channel [Fig. 2(b)]. The left ventricle was unchanged, and function in the territory of the left anterior descending coronary artery appeared normal at rest. Both arteries were successfully treated by angioplasty. The coronary wedge pressure $\mathrm{e}^{[4]}$ was $35 \mathrm{~mm} \mathrm{Hg}$ in the left anterior descending artery but was only $20 \mathrm{mmHg}$ in the right coronary artery after angioplasty of the left lesion because the ostium of the collateral marginal branch was occluded by the inflated balloon. At the end of the procedure, complete disappearance of collateral flow was noted. A repeat stress test was negative, and the patient was again asymptomatic. At followup angiography six months later, both dilated sites showed good patency and the collateral channel was not opacified in either direction (Fig. 3). The patient remained asymptomatic and the stress test negative.

\section{Comment}

Collaterals have been shown to become angiographically visible in response to spasm, stenosis or occlusion $^{[5-\pi]}$. However, without sufficiently severe coronary stenosis no conclusions can be drawn from the absence of angiographically visible collaterals, since they will only be apparent when the 


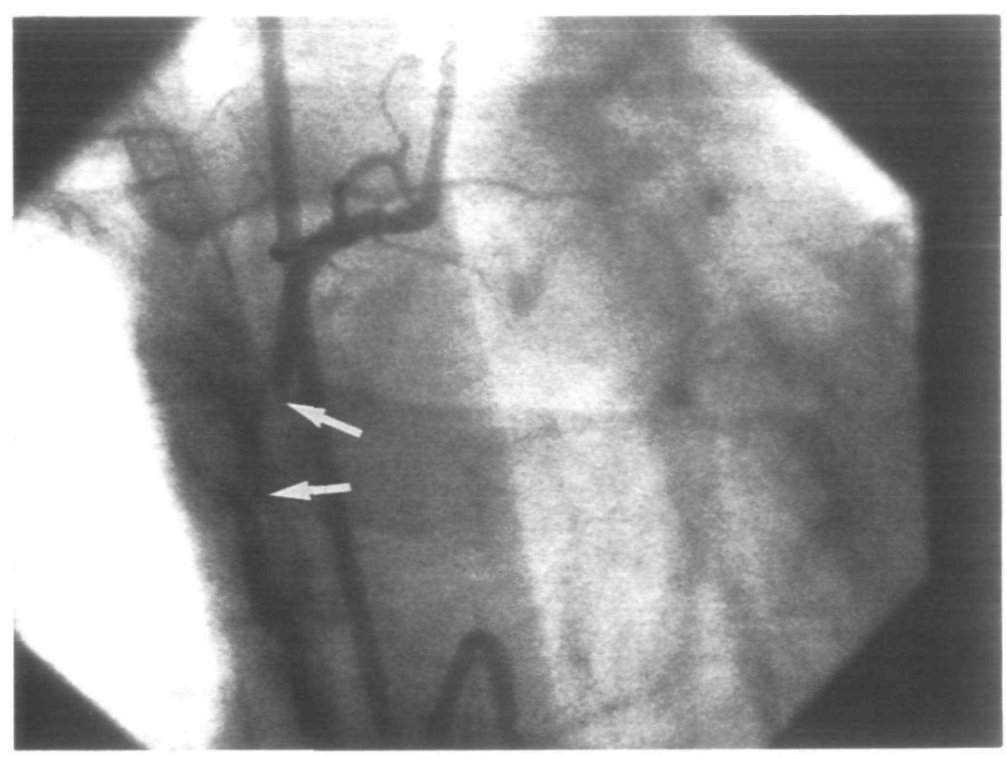

(a)

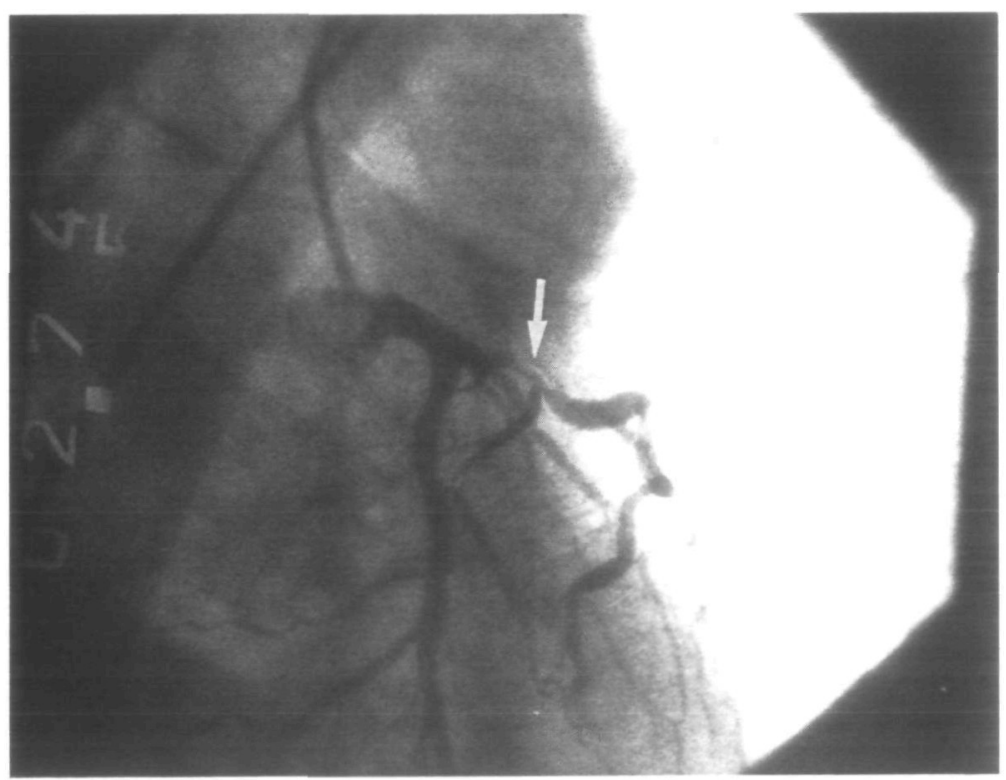

(b)

Figure 1 (a) $30^{\circ}$ right anterior oblique view of the right coronary artery showing the intial high grade tandem stenosis (arrows) at the time of left to right collateral flow. (b) $30^{\circ}$ right anterior oblique view with $30^{\circ}$ caudal tilt showing severe proximal stenosis of the left anterior descending coronary artery (arrow) at the time of reversed right to left collateral flow

gradient across them generates sufficient flow. This gradient is transiently increased by balloon inflation during angioplasty, and collaterals have been shown by contralateral injection to then become visible $e^{[4,8]}$. This collateral flow has been called 'recruitable' and its existence can be pre- dicted by an elevated coronary wedge pressure distal to the treated lesion ${ }^{[4]}$. Coronary wedge pressure is the pressure recorded distal to a stenosis while the inflated balloon occludes the coronary artery. Its level varies with aortic pressure but for patients in a stable haemodynamic state it is 
essentially determined by the collateral flow reaching the artery distally to the lesion ${ }^{[4,9]}$. One of the limitations of coronary wedge pressure measurement is illustrated by the present case: because the collateral channel opened into the right coronary artery immediately distal to the stenosis, flow through it was impeded during balloon inflation and this led to spuriously low values for the wedge
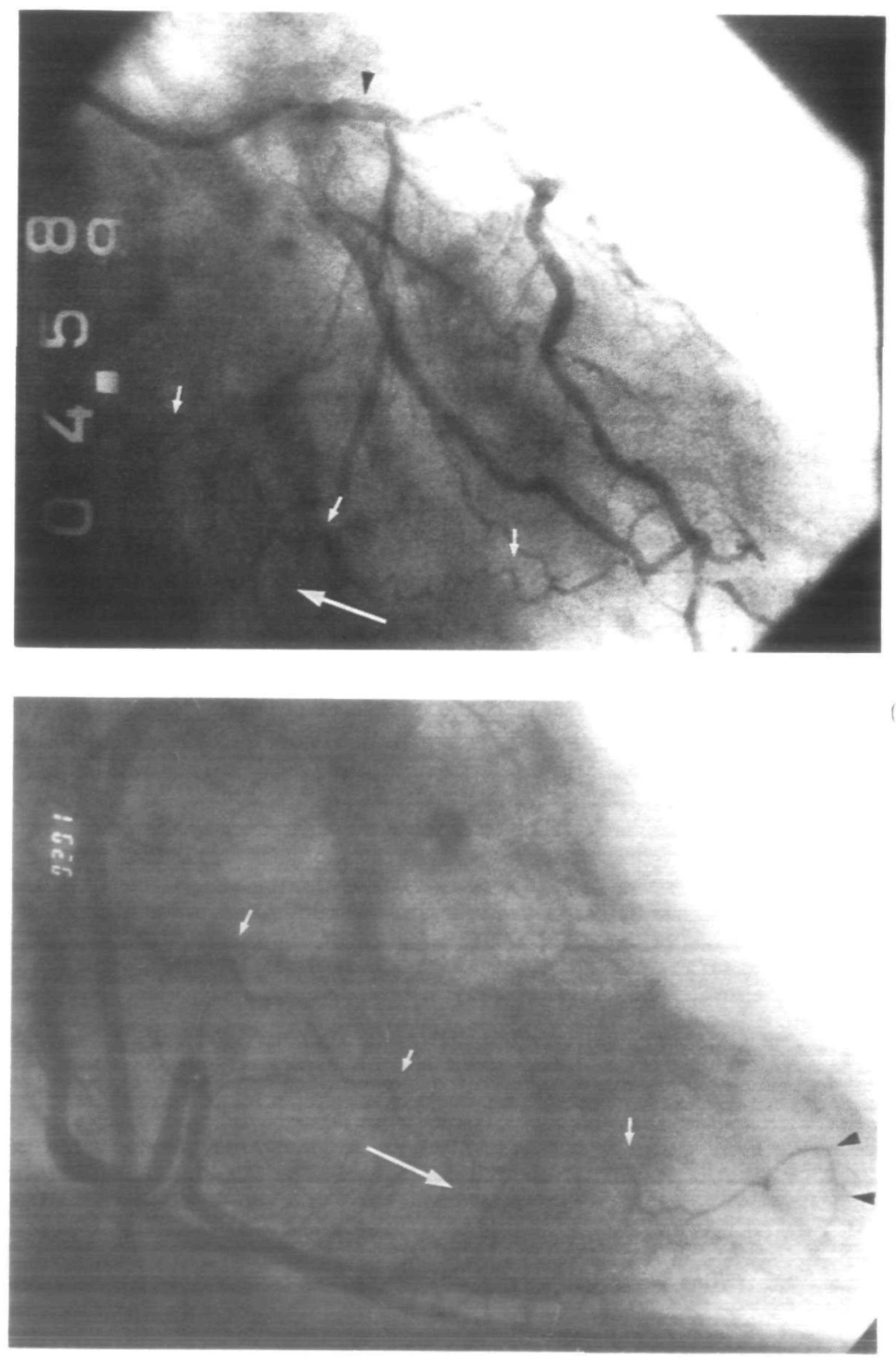

Figure $230^{\circ}$ right anterior oblique view showing collateral flow (long arrow) in the nght marginal branch (short arrows). (a) The vessel is filled from the left anterior descending coronary artery before angioplasty of the right coronary artery. There is a non-significant stenosis of the proximal left anterior descending (arrowhead). (b) Seven months later, the same collateral channel is filled from the right coronary artery and opacifies the distal left anterior descending artery (double arrowhead) because of the now severe proximal left anterior descending coronary artery stenosis. 

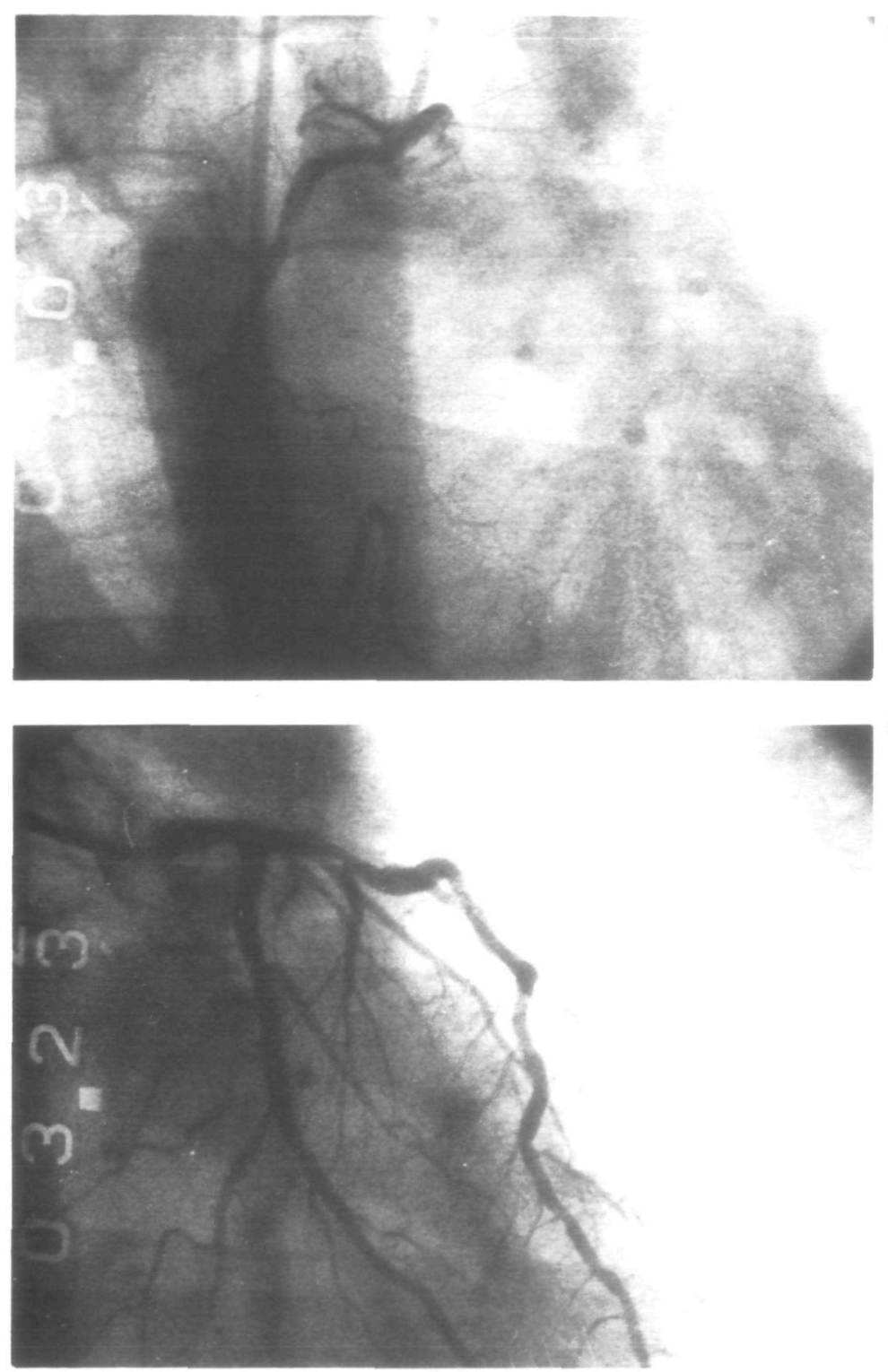

Figure 3 Follow-up angiography six months after the second procedure. (a) $30^{\circ}$ right anterior oblique view of the right coronary artery. (b) $30^{\circ}$ right anterior oblique view of the left anterior descending artery. No collaterals are now visıble and there is no restenosis of either lesion

pressure in the right coronary, when compared to the values obtained from the left anterior descending coronary artery.

In the present case, progression of the lesion in the left anterior descending coronary artery led to spontaneous flow reversal in a collateral branch that had remained in a 'standby' state after the original right coronary artery stenosis had been treated with angioplasty. This illustrates the fact that preexisting collateral channels can be recruited at a later stage by progression of coronary disease. The observed flow reversal has not been reported previously in association with angioplasty. It confirms the data obtained from patients after coronary artery bypass grafting suggesting that pressure gradients were the sole determinants of the 
direction of flow in collateral channels ${ }^{(2)}$. Recently, a case of spontaneous flow reversal through collateral channels after a follow-up of 6 years has been reported $^{[3]}$.

Evaluation of the degree of protection against ischaemia that is afforded by collateral flow is difficult. Our patient had no change in his resting left ventricular function at rest despite the development of a severe proximal left anterior descending lesion. A coronary wedge pressure of $35 \mathrm{mmHg}$ such as was measured in the present case should maintain significant residual flow in the event of total occlusion $^{[4]}$.

Although Cashin et al.$^{[10]}$ have reported a rate of progression of non-significant coronary lesions of only $3 \%$ during a 37 months follow-up, it has also been shown that such moderate lesions may progress to sub-total or total occlusion in a sudden and unpredictable manner ${ }^{[1]}$, as was the case in our patient. Securing the potential of inverted collateral flow may accasionally constitute an added benefit of angioplasty, particularly when 'non-significant' lesions are seen in the vessel from which the collaterals originate.

\section{References}

[1] Damiano RJ, Ungerleider RM, Lofland GK, Williams JM, Quick G, Cox JL. Reversal of flow through chronic coronary collateral vessels. J Surg Res 1981; 30: 544-52.

[2] See JR, Marlon AM, Feikes HL, Cosby RS. Effect of direct revascularization surgery on coronary collateral crrculation in man. Am J Cardiol 1975; 36: 734-8.

[3] Thomas JD, Gundel WD. Myocardial preservation with alternative coronary artery occlusion and reversal of flow through collateral vessels. Cath Cardiovase Diag 1986; 12: 327-9.

[4] Meter B, Luethy P, Finci L, Steffenino GD, Rutishauser $W$. Coronary wedge pressure in relation to spontaneously visible and recruitable collaterals. Circulation 1987; 75:906-13.

[5] Elayada McAA, Mathur VS, Hall RJ, Ali Massumı G, Garcia E, de Castro MC. Collateral circulation in coronary artery disease. Am J Cardiol 1985; 55: 58-60.

[6] Schwarz H, Leiboff RH, Bren GB et al. Temporal evolution of the human coronary collateral circulation after myocardial infarction. J Am Coll Cardiol 1984; 4: 1088-93.

[7] Takeshita A, Kolwaya Y, Nakamura M, Yamamoto K, Torii S. Immediate appearance of coronary collaterals during ergonovine-ınduced arterial spasm. Chest 1982; 82. 319-22.

[8] Rentrop KP, Cohen M, Blanke H, Philips RA. Changes in collateral channel filling immediately after controlled coronary artery occlusion by an angioplasty balloon in human subjects. J Am Coll Cardıol 1985; 5: 587-92

[9] Urban P, Meier B, Finci L, de Bruyne B, Steffenino G, Rutishauser W. Coronary wedge pressure: a predictor of restenosis after balloon angioplasty. J Am Coll Cardiol (in press).

[10] Cashin LW, Sanmarco ME, Nessim SA, Blankenhorn DH. Accelerated progression of atherosclerosis in coronary vessels with minimal lesions that are bypassed. $\mathrm{N}$ Engl J Med 1984; 311: 824-8.

[II] Bruschke AVG, Wijers TS, Kolsters W, Landmann J. The anatomic evolution of coronary artery disease demonstrated by coronary angiography in 256 non operated patients. Circulation 1981; 63. 527-36. 